\title{
Gender effect on neurodegeneration and myelin markers in an animal model for multiple sclerosis
}

\author{
Alessandro Massella², Giulia D'Intino², Mercedes Fernández ${ }^{1}$, Sandra Sivilia ${ }^{2}$, Luca Lorenzini', Silvia Giatti ${ }^{3}$, \\ Roberto C Melcangi ${ }^{3}$, Laura Calzà ${ }^{1,2}$ and Luciana Giardino ${ }^{1,2^{*}}$
}

\begin{abstract}
Background: Multiple sclerosis (MS) varies considerably in its incidence and progression in females and males. In spite of clinical evidence, relatively few studies have explored molecular mechanisms possibly involved in genderrelated differences. The present study describes possible cellular- and molecular-involved markers which are differentially regulated in male and female rats and result in gender-dependent EAE evolution and progression. Attention was focused on markers of myelination (MBP and PDGF $\alpha$ R) and neuronal distress and/or damage (GABA synthesis enzymes, GAD65 and GAD67, NGF, BDNF and related receptors), in two CNS areas, i.e. spinal cord and cerebellum, which are respectively severely and mildly affected by inflammation and demyelination. Tissues were sampled during acute, relapse/remission and chronic phases and results were analysed by two-way ANOVA.

Results: 1. A strong gender-dependent difference in myelin (MBP) and myelin precursor (PDGF $\alpha$ R) marker mRNA expression levels is observed in control animals in the spinal cord, but not in the cerebellum. This is the only gender-dependent difference in the expression level of the indicated markers in healthy animals; 2. both PDGF $\alpha$ R and MBP mRNAs in the spinal cord and MBP in the cerebellum are down-regulated during EAE in genderdependent manner; 3 . in the cerebellum, the expression profile of neuron-associated markers (GAD65, GAD67) is characterized by a substantial down-regulation during the inflammatory phase of the disease, which does not differ between male and female rats (two-way ANOVA); 4. there is an up-regulation of NGF, trkA and p75 mRNA expression in the early phases of the disease (14 and 21 days post-immunization), which is not different between male and female.
\end{abstract}

Conclusions: It is reported herein that the regulation of markers involved in demyelination and neuroprotection processes occurring during EAE, a well-established MS animal model, is gender- and time-dependent. These findings might contribute to gender- and phase disease-based therapy strategies.

Keywords: experimental allergic encephalomyelitis, gender-related, rat, spinal cord, cerebellum, neurotrophins and related receptors

\section{Background}

Multiple sclerosis (MS) is an inflammatory demyelinating disease of the central nervous system (CNS), which can progress over decades. The progressive failure of remyelination leads to the cumulative loss of axons, grey matter atrophy and prevalent neurodegeneration responsible for chronic disability and cognitive decline [1]. There is a considerable difference in the way MS affects females

\footnotetext{
* Correspondence: luciana.giardino@unibo.it

${ }^{1}$ Health Sciences and Technology - Interdepartmental Center for Industrial Research (HST-ICIR), University of Bologna, Via Tolara di Sopra 50, 40064

Ozzano Emilia, Italy

Full list of author information is available at the end of the article
}

and males, as has been highlighted by epidemiology studies and MRI analyses [2-4]. The way of gender-influence in MS is complex and still obscure. From a pathogenic point of view, females tend to have stronger Th1mediated immune responses and are more prone to develop autoimmune diseases, including MS [5]. However, gender might influence white matter establishment and maintenance of the mature structure of white tracts, thus affecting their repair capability. A review of in vivo imaging studies suggests that gender-related differences in white matter in the human brain exist in healthy subjects [6] and affect in particular age-related changes in
C Biomed Central

(C) 2012 Massella et al; licensee BioMed Central Ltd. This is an Open Access article distributed under the terms of the Creative Commons Attribution License (http://creativecommons.org/licenses/by/2.0), which permits unrestricted use, distribution, and reproduction in any medium, provided the original work is properly cited. 
precentral, cingulate, and anterior temporal white matter areas [7]. As well as in the normal brain, white matter pathology seems also to differ in males and females in several neurological and psychiatric conditions. For example, in schizophrenia there is a subtle and genderdependent alteration in the forebrain commissures, and the neurotoxic effect of metamphetamine on frontal white matter seems to be less prominent in women than in men [8]. Sex differences in lesion size, neuronal cell loss, and mortality rates have been observed after ischemia and trauma [9]. Moreover, a gender effect in the progression of several neurodegenerative diseases has been noted. Epidemiological data point to women's proneness to Alzheimer's disease [10], and indicate that after traumatic brain injury (TBI) women show better recovery than men [9].

Apart from this clinical evidence, on which several gonadal steroids-oriented clinical trials have been based [11], relatively few studies have explored possible molecular mechanisms involved in gender-related differences. In this context, there has been much speculation concerning the gonadal hormone role in immune function and cytokines production during inflammation, myelination, and neurodegeneration/neuroprotection $[4,5,12]$, but direct evidence regarding gender-related differences in these and other critical molecular and cellular hallmarks of the diseases is still very scanty.

We are exploring possible molecular determinants for gender-dependent differences in inflammatory demyelinating diseases using experimental allergic encephalomyelitis (EAE) in rats as a disease model for MS. EAE induced in Dark Agouti rats is Th1 mediated, having a relapsingremitting course, and comprises also persistent demyelination, remyelination, neuronal distress and cognitive defects [13-18]. In this model, we have demonstrated by liquid chromatography-tandem mass spectrometry that the levels of neuroactive steroids display sex, regional and temporal differences in both control and EAE, and these changes did not correlate to the plasma levels of gonadal hormones $[19,20]$.

In this paper data are presented regarding molecular markers for oligodendrocyte precursor cells, myelin proteins, neurotransmitters and neurotrophins in the course of EAE. Attention was focused on the spinal cord as a white matter-rich area in which most of the tissue is occupied by heavily myelinated tracts that is severely affected by inflammation and demyelination, and on the cerebellum as a grey matter-rich area since ataxia is a common symptom in EAE rats, and a cerebellar cortical atrophy has been described late in the disease in spite of poor inflammation and demyelination [21].

\section{Results}

\section{Animals and disease progression}

The clinical profile of EAE is reported in Figure 1, where neurological disability score (A) and body weight graphs (B) are shown. Animals develop clinical signs for EAE starting from 7-8 days post-immunization (DPI), after which disease progressed rapidly until 14 DPI (acute phase). The first regression is not complete and at 21 DPI there is a relapse, which is not so severe as the acute phase. The recovery phase is followed until 40 DPI, when a very slight disability still persists. The statistical analysis by two-way ANOVA indicates that the course of the disease is different between male and female rats $(\mathrm{p}=$ 0.0028). The body weight curves show the physiological profile in male and female control rats, and the expected gain arrest in the acute phase, which is followed by a partial recovery $(\mathrm{B})$.

Histopathology was analysed at 14 DPI. At this stage, a severe and diffuse inflammatory cellular infiltrate was observed in the spinal cord (Figure 2A: control; Figure 2B-D: EAE) in perivascular and intraparenchymal areas. The astroglial reaction was also analysed by
A.

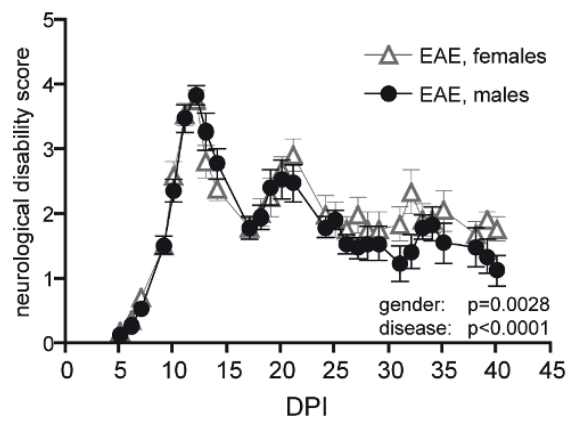

B.

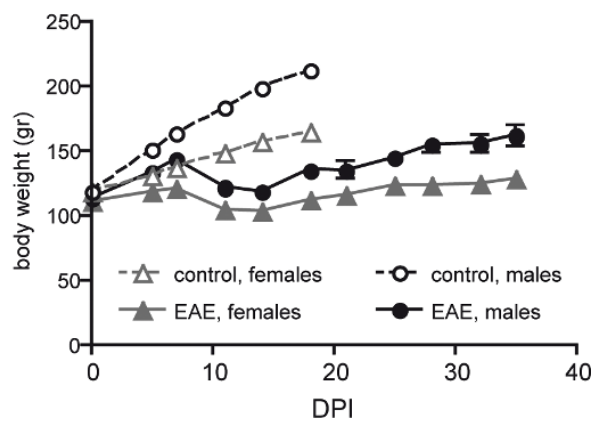

Figure 1 Clinical score evolution (A) and body weight variations (B) in experimental animals (control female: white triangle, control male: white circle, EAE female: black triangle, EAE male: black circle). Significant differences were observed in the clinical disability score between male and female animals (two-way ANOVA, gender effect, ${ }^{* *} \mathrm{p}=0.0028, \mathrm{~F}(1,649)=9.027$; days post-immunization (DPI) effect, ${ }^{* * *} \mathrm{p}<$ $0.0001, F(27,649)=54.32$. 

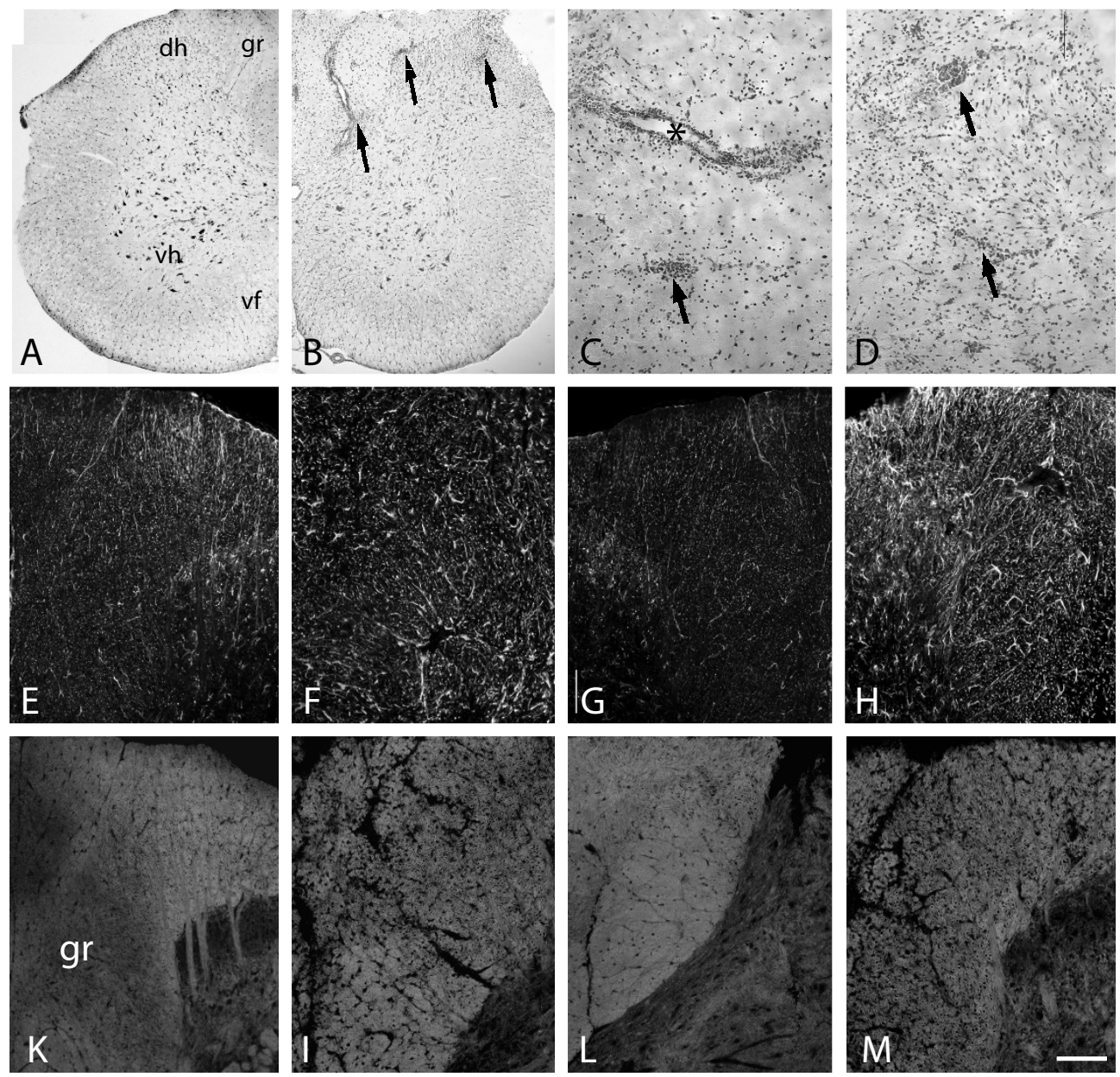

$\mathrm{N}$

score/section

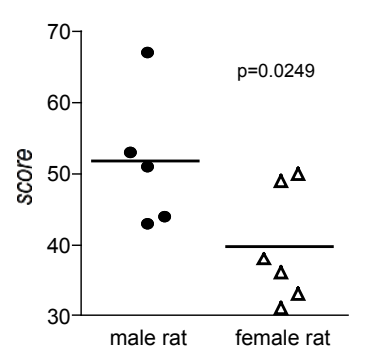

O

GFAP-IR

gracile fasciculus

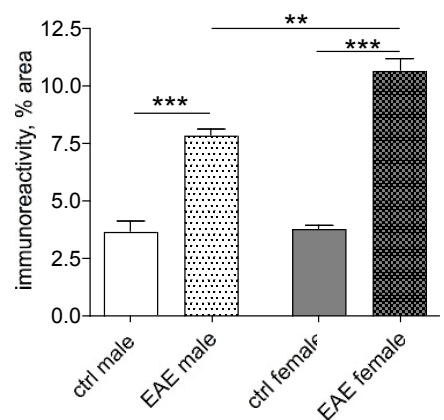

$P$

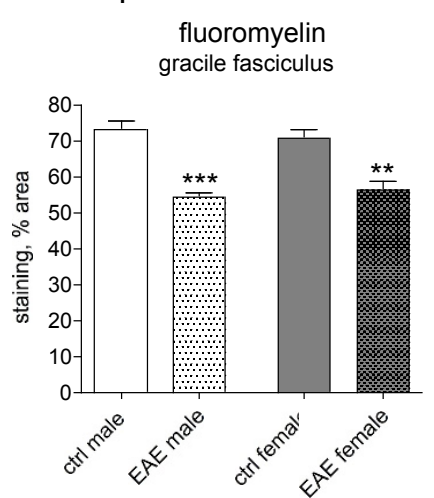

Figure 2 Histopathology of the spinal cord in control and EAE animals was performed by E\&E (A-D), GFAP-immunostaining for astroglial reaction $(\mathrm{E}-\mathrm{H})$ and FluoroMyelin staining for white tractd and myelin sheaths (K-M and related inserts). Micrograph in $A$ illustrates a spinal cord hemi-sections in control, male rat; micrograph in B a spinal cord hemi-sections showing the extensive inflammatory infiltrates in $E A E$, as detailed in high power micrographs in $C$ and $D$. Arrows indicate the intraparenchimal infiltrates asterisk in $C$ a perivascular infiltrate. Image analysis indicates that there is a difference in the extension of inflammation infiltrate in female vs male EAE animals ( $N$, Student's $t$ test, $p=0.00249$ ). Micrographs from $E$ to $H$ illustrate the astroglial reaction in EAE animals ( $F$ : female; $H$ : male) with control animals (E: female: G: male). Image analysis indicates that astroglial reaction is stronger in female than in male EAE animals $(\mathrm{O}$, one way ANOVA and Tukey multiple comparison test, $\left.{ }^{* *} \mathrm{p}<0.01 ;{ }^{* * *} \mathrm{p}<0.001\right)$. Micrographs from $\mathrm{K}$ to $\mathrm{M}$ illustrate white matter in EAE (I: female; M: male) compared with control animals (K: female; L: male). The color inserts refer to high power magnification, to shown the myelin sheath morphology. The original image has been processed using a deconvolution procedure. Image analysis indicates that demyelination is not different in female and male EAE animals (one way ANOVA and Tukey multiple comparison test, ${ }^{* *} p<0.01 ;{ }^{* * *} p<0.001$ ). Graph bars: M, $100 \mu m$; color insert $10 \mu \mathrm{m}$. 
GFAP-immunostaining (Figure 2E-H) and demyelination by FluoroMyelin histochemistry (Figure 2K-M). Morphometric analysis of the investigated markers is reported in Figure 2N-P. The semiquantitative evaluation of the inflammation score reveals a slight but significant difference between male and female rats, having the female animals a lower score (Figure $2 \mathrm{~N}$ ). The astroglial reaction observed in male and female rats during EAE was stronger in female than in male rats (Figure 2O). Demyelination, as analysed in the gracile fasciculus of the lumbar spinal cord, was no different in male and female rats.

At this stage, and as already reported in previously published paper [13] very few cellular infiltrates were found in cerebellum and cerebral cortex (not shown).

\section{Myelin markers}

In order to investigate possible gender effects on demyelination/remyelination during EAE in Dark-Agouti rats, the expression level of myelin markers was analyzed in both male and female rats at the different phases of the EAE, in spinal cord and cerebellum. In particular, mRNA expression level was analyzed for PDGF $\alpha$, which is a marker for the oligodendrocyte precursor cells (OPCs) responsible for myelin repair in the mature CNS [22] and MBP, which is one of the most abundant among the myelin proteins [23]. In the spinal cord, PDGF $\alpha$ R mRNA expression in healthy males is around 2.5 times higher than in healthy females ( $p=0.0175)$, whereas the MBP mRNA level is 5 times higher in males than in females $(p=0.0004)$ (Figure $3 \mathrm{~A}, \mathrm{~B}$ ). In both sexes, the expression of both genes was down-regulated in all phases of the disease (Figure $3 \mathrm{C}, \mathrm{D}$ ) and a significant difference was observed between females and males (two-way ANOVA and Bonferroni post-test). PDGF $\alpha \mathrm{R}$ mRNA down-regulation is stronger in male than in female at 14 and 21 DPI. MBP mRNA expression level differs between male and female at 21 and 40 DPI. The histochemical analysis of myelin during the acute phase of EAE indicated that the decrease in myelin staining in the gracile fasciculus was comparable in both male and female rats (Figure $2 \mathrm{C}$ ).

To determine whether the sex-dependent difference in MBP mRNA expression also had an impact on protein content, MBP protein levels were measured in the spinal cord of control healthy rats using Western blot. The 17.5, 18.5 and 21.5 isoforms were studied, and a representative Western-blot experiment has been included in Figure 4 (D). No differences between female and male rats were observed in any of the investigated isoforms (Figure 4A, B, C). A morphometric analysis of the myelin sheath in male and female rats was also performed by measuring the Gratio of the lateral, dorsal and ventral funiculus of the lumbar spinal cord in confocal images of FluoroMyelin staining. No differences between male and female rats were observed (data not shown).

In the cerebellum, no significant changes were observed in the expression of PDGF $\alpha$ R mRA between healthy male and female rats and during the course of EAE (Figure $5 \mathrm{~A}, \mathrm{C})$. On the contrary, MBP mRNA expression level was down-regulated during EAE in both females and males. Significant differences were observed in the expression of the MBP gene in EAE animals (Figure 5B, D) at $40 \mathrm{DPI}$ between females and males, being lower in female than male rats (Bonferroni test, $* \mathrm{p}<0.01$ ).

\section{GAD, neurotrophins and related receptors}

In order to investigate markers for neuronal distress/ lesion, the expression level for mRNAs encoding for GABA synthesis enzyme and neurotransmitter and neurotrophins was analyzed. No gender effect was observed in the expression of mRNA encoding for the enzymes GAD65 and GAD67 either in healthy or EAE animals (Figure 6A, B). However, the expression of GAD65 and GAD67 mRNA during EAE was down-regulated in both male and female rats. Significant differences were observed at different phases of EAE. GAD65 and GAD 67 mRNA levels displayed a recovery at $40 \mathrm{DPI}$.

The expression of BDNF, NGF neurotrophin receptors trkA (high-affinity NGF receptor) and p75 (low affinity NGF and BDNF receptor) was also studied during EAE in both sexes in the cerebellum. No gender effect for any of the investigated mRNAs was found in healthy animals (Figure 7A, B, C, D). BDNF mRNA expression was not significantly changed during the course of EAE (Figure 7E) in both male and female rats. On the contrary, there was a significant up-regulation of NGF mRNA expression level in the acute, inflammatory phase of the disease in both male and female rats (Figure 7F, 14 DPI), which was partly attenuated, but not resolved, in the course of the disease in female rats and resolved already at 21 days in male rats. A slight, but significant and stable up-regulation of the NGF low-affinity receptor p75 mRNA expression was observed in both female and male rats (Figure 7G). An up-regulation of the NGF high-affinity receptor trkA mRNA expression level was also found in female and male (Figure 7H).

\section{Discussion}

Gender bias in autoimmune diseases is a well-known and hitherto unexplained fact. In particular, MS is more prevalent in females than in males, and this female predominance increases as time goes by. Gender appears to play a critical role also in the progression of MS, suggesting that not only immune reaction, but also remyelination, axonal pathology and neural damage might be gender-dependent [24]. In all cases, the histopathological and molecular 


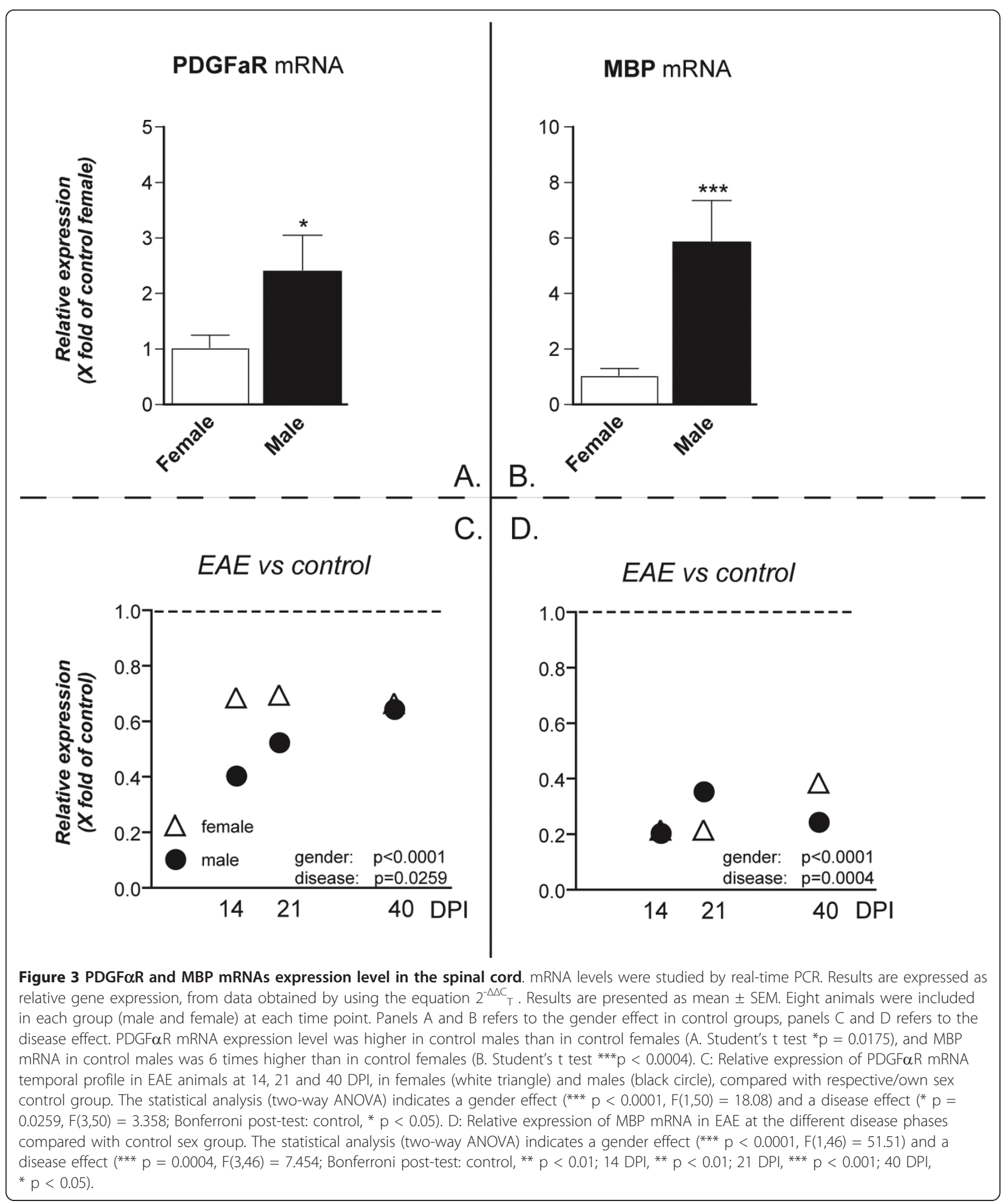

mechanisms underlying the inherent differences in male and female MS are still obscure [25].

In the present study molecular markers for myelin and grey matter that are differentially regulated in male and female rats in the experimental model of the disease have been described. Two areas were investigated: the spinal cord, which is the area with extensive inflammation and demyelination, and the cerebellum, in view of 


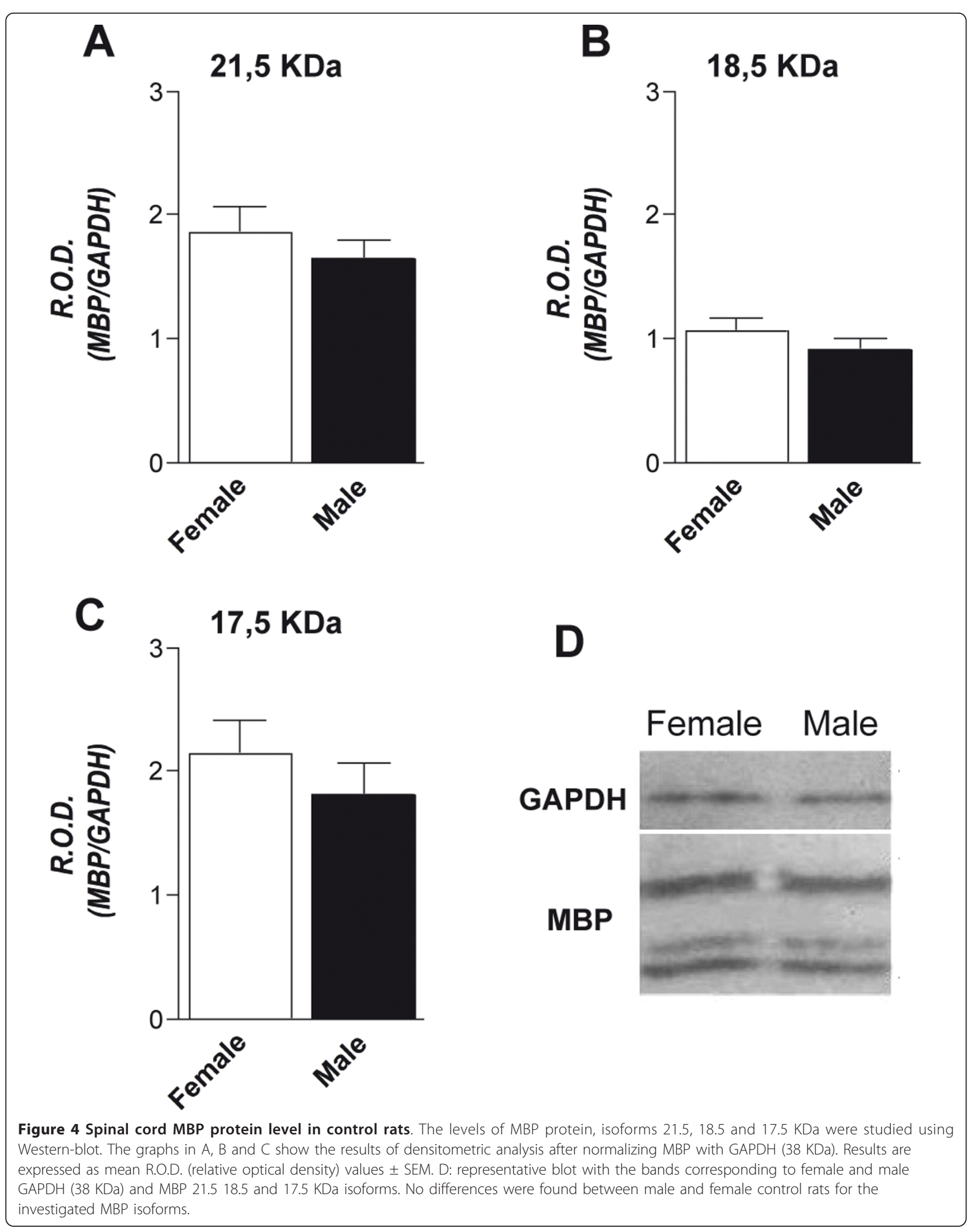




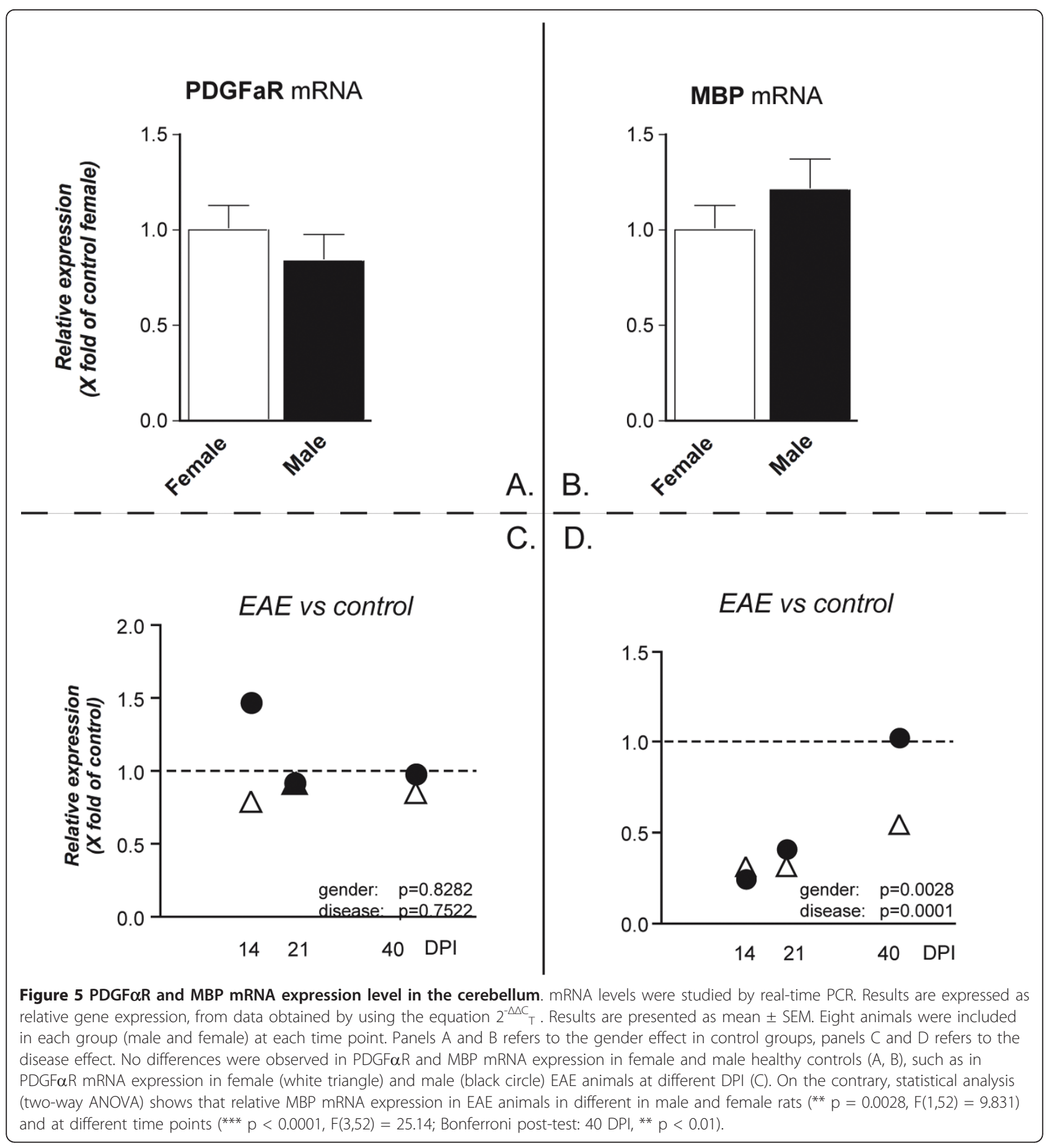

the ataxia symptom in EAE, where inflammatory cellular infiltrates are scare in this disease model [26]. While the clinical profile of the disease differs between sexes being more severe in female than male rats, the inflammatory cellular infiltration in the spinal cord is lower in females, but produces a stronger astroglial reaction than in males. Moreover, disease-induced alteration of several markers is different between the two sexes. In particular, a strong gender-dependent difference in MBP and PDGFaR mRNA expression level in the spinal cord of healthy animals was found, which correspond to a different regulation during the disease.

\section{EAE in male and female Dark Agouti rats}

Here we confirm that both male and female Dark Agouti rats are highly susceptible to EAE [26]. While the clinical 


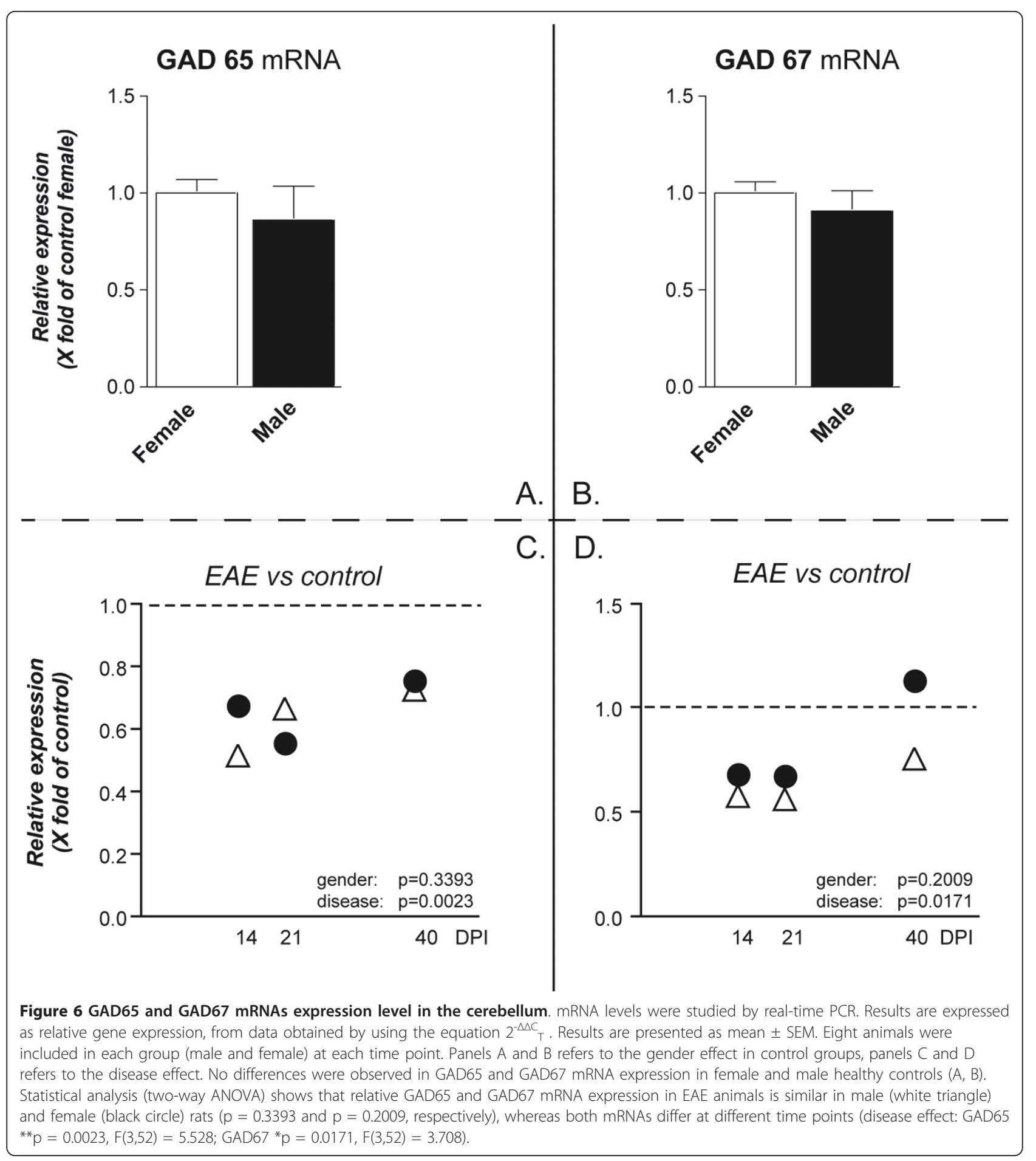

score profile in the acute phase is similar in males and females, male rats show a more pronounced recovery than female rats. In this EAE model, a massive infiltration by inflammatory cells, and a massive demyelination were observed in the spinal cord, whereas small and localized lesions were spread over the main white tracts, including the cerebellar peduncoli, corpus callosum and optic nerve $[15,16,26]$. The remyelination process starts quite early also in Dark Agouti rats, but it is not yet complete at 40 DPI [16]. In spite of the fact that severity of inflammatory infiltrate in the spinal cord is lower in female compared to male rats, astroglial reaction is more pronounced in female than in male rats. This could be related to humoral rather cellular immune reaction. 


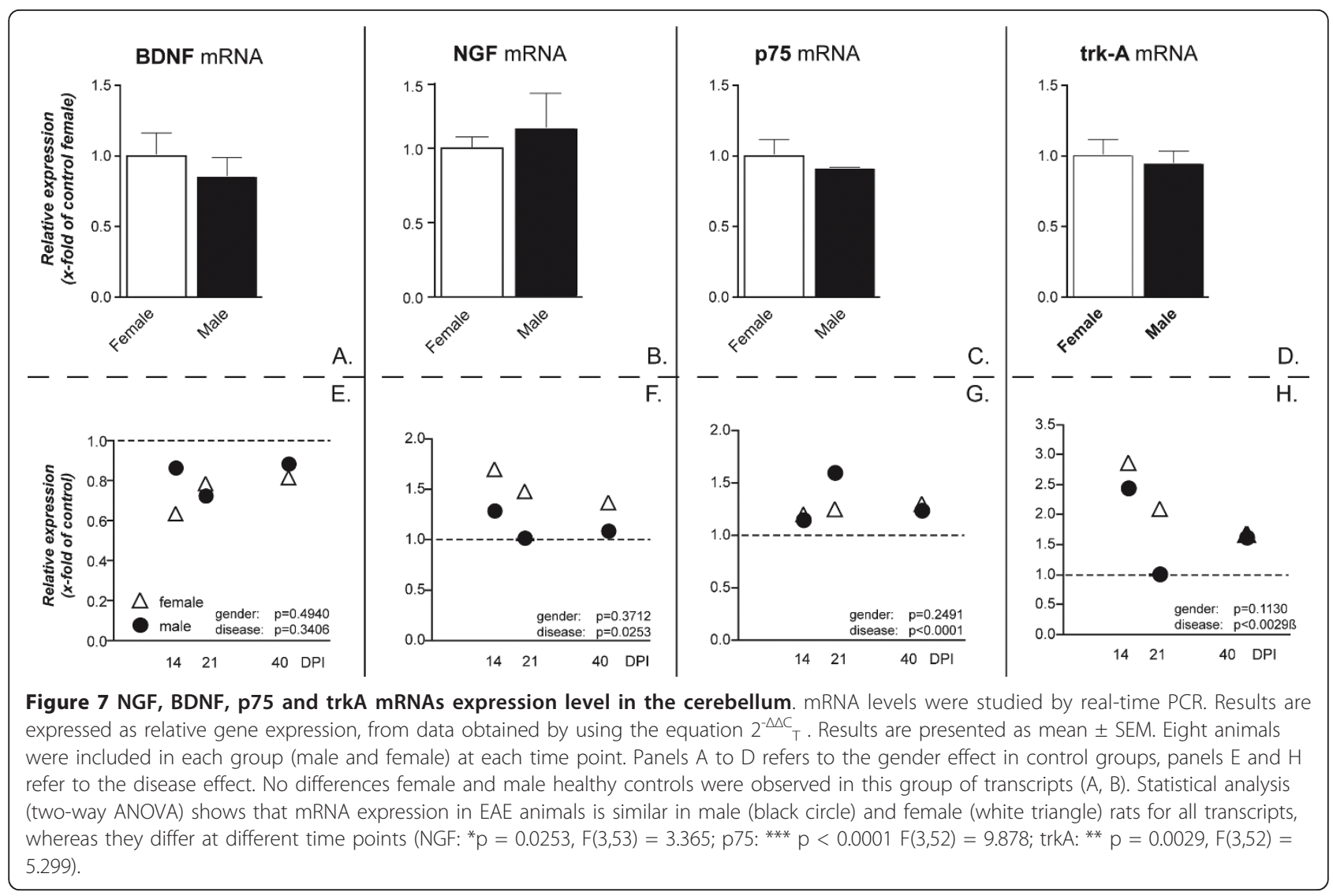

Overall, the females of all the species used for MS models display stronger immune responses than males [26-28]. This is attributed to cytokines production $[29,30]$. For example, cytokine IL-13 is implicated in gender differences in EAE severity in C57BL/6 mice, where the absence of the anti-inflammatory IL-13 entails lower susceptibility to EAE in females vs males or WT females with normal levels of IL-13 [31].

\section{Gender-dependent differences in white matter during health and inflammatory-demyelinating disease}

When comparing the expression level of the genes included in the study in male vs female healthy rats, the most significant result was the 5-fold higher MBP and the 2.5-fold higher PDGF $\alpha$ R expression in males than females in the spinal cord, but not in the cerebellum. This difference is not present at protein level, and, more generally, no significant differences in myelin sheaths in the spinal cord were found between male and female rats. This result might suggest that MBP synthesis could be regulated in a different way at post-transcriptional and translational levels in males and females. In fact, mRNA levels and protein levels do not always correlate $[32,33]$ and this might be due to the post-transcriptional mechanisms playing and/or to the different in vivo half life of proteins. Gonadal steroid and neurosteroid may elicit effects through nongenomic mechanisms via ERs localized on the plasma membrane, and ligand-independent pathways to activate ERs have been also described [34]. Moreover, the mechanisms controlling the rates of degradation/synthesis for a given mRNA and protein are not homogeneous, even within proteins that have similar functions [33]. Technical limits of the methods for quantifying mRNA and proteins should also be taken into account.

More generally, the issue of gender-related difference in the anatomy of white tracts is complex and controversial. The gender-dependent difference in PDGF $\alpha$ R and MBP mRNA in the spinal cord correlates with data from Cerghet et al. $[35,36]$ in mice. They found that the density of oligodendrocytes and the content of several myelin proteins in white tracts is higher in males than in females, whereas the lifespan of oligodendrocytes is shorter in females than in males, thus suggesting that myelin turnover is greater in females than in males. It may thus be argued that males have a greater functional reserve than females, whereas females have a greater vulnerability related to higher myelin protein turnover.

We and others already described the variation of MBP protein content, such as different markers for OPCs in male and female rats during EAE $[13,15,16,37]$. In this 
study we report that there is a gender-dependent difference in the regulation of PDGF $\alpha \mathrm{R}$ and MBP during the experimental disease, involving both genes in the spinal cord, and MBP, only in the cerebellum. This correlates with other reports describing differences in remyelination in old male and female rats [38] and in cuprizone intoxication model (reversible inflammatory demyelination) [39].

\section{Neurotrophins and neuronal markers in inflammatory- demyelinating diseases}

The EAE model in rodents (and primates) allows neuronal distress/damage to be investigated. We already described how the expression level of the acetylcholine synthesis enzyme choline acetyltransferase mRNA level was transiently reduced in motor neurons in the spinal cord [17] and in cholinergic neuron of the basal forebrain [18] during EAE. Here investigation was focused on cerebellum, which is involved in motor symptoms in EAE. In spite of scant inflammation and demyelination, a grey matter atrophy [21] and a Purkinje cell loss [40] has been described in the cerebellum. As index of neuronal injury, we investigated the expression level of the mRNAs encoding for the GABA synthesis enzyme $\gamma$ aminobutyric acid decarboxylase (GAD) [41]. A transient down-regulation of both GAD65 and GAD67 was observed in male and female EAE rats, thus confirming that the acute phase of the disease is associated with reversible neuron distress.

Due to the neurotrophins role as endogenous neuroprotectors, their expression levels were investigated during EAE, focusing on NGF and BDNF. Previous results from our laboratory have described higher levels of NGF in certain brain areas, like the thalamus and cerebral cortex, but not the spinal cord, in EAE compared to healthy rats, associated to a strong up-regulation of p75and trkA-like immunoreactivity [13]. This up-regulation diminishes over time and a drop in NGF mRNA expression level was reported in the cerebral cortex at 104 DPI [18]. Here we confirm the up-regulation of NGF and its high-affinity receptor trkA mRNA in the cerebellum in both male and female in the early, inflammatory phase of EAE, while BDNF is down-regulated at the same times. NGF, but also BDNF, modulate inflammation and immune cell function in many diseases [42-45]. Both the high and low affinity NGF receptors are widely expressed in the immune system, thus indicating a potential for responding to this neurotrophin through an autocrine mechanism $[43,45]$. NGF increase during EAE may possibly also result in increased neuroprotection [46], working with the marmoset model, showed that NGF icv administration delayed the onset of clinical EAE, and also prevented the full development of EAE lesions. NGF administration also influences EAE development and progression in rats [47] by reducing the severity of the disease compared to that in saline treated EAE mice.

The low-affinity receptor p75 is also up-regulated. Notably, the up-regulation of p75 in Purkinje neurons has been described in EAE [48]. The p75 up-regulation in EAE could be related to the Purkinje neurons death and cerebellar atrophy, since p75 can induce autophagy and death in these cells [49].

Since the original report describing the different content of NGF in the submaxillary gland in male and female mice [50], many other reports have illustrated sexually dimorphic distribution of NGF in tissues and plasma of different animal species [51-53]. The cerebellum and particularly the Purkinje cells have been recognized as a major source for neurosteroid production [54], and we reported that neurosteroids are differentially regulated in the cerebellum of control male and female rats, such as during EAE [20]. Our mRNA data indicate that there are no sex differences in the NGF and BDNF levels in cerebellum either in healthy and EAE rats, thus confirming previous reports suggesting that neurotrophin levels do not correlate with estrogen levels in females or with estrogen or testosterone levels in males at this age $[55,56]$.

\section{Conclusions}

Differences in vulnerability and disease evolution have already given rise to clinical trials for MS based on gonadal steroids. With regard to animal models of inflammatory-demyelinating diseases, it has recently been reported that the combined administration of 17 beta-estradiol and progesterone prevents cuprizone-provoked demyelination of the corpus callosum in male mice [57]. A similar effect of combined treatment was also found in MOG (40-45)-induced EAE mice [58]. However, rational future prospects regarding the use of sex steroids as adjuvant therapy in MS should be based on the identification of the pathological process, cell type, and molecular pathways positively affected by steroids with regard to disease onset and progression. This study provides a description of the gender-dependent and disease-dependent regulation of markers for these different processes in a well-established animal model, suggesting that demyelination/remyelination might be a target for gender-dependent therapies.

\section{Methods}

\section{Animals, EAE induction, groups size}

Dark-Agouti (Harlan, Italy) male and female rats, 150175 g body weight were used in this study. In both female and male rats, a group was sensitized with a medium containing $0.15 \mathrm{~g} / \mathrm{ml}$ guinea pig spinal cord tissue in complete Freund's adjuvant (CFA, Sigma), 50\% v/ 
$\mathrm{v}$, to which $5 \mathrm{mg} / \mathrm{ml}$ of heat-inactivated Mycobacterium (Difco H37Ra) was added. Un-injected rats were used as controls. Rats were regularly weighed and examined for clinical signs of EAE by a trained observer according to a semiquantitative score: $1=$ loss of tail tone, $2=$ mono or bilateral weakness of hind legs or middle ataxia, $3=$ ataxia or paralysis, $4=$ severe hind legs paralysis, $5=$ severe hind leg paralysis and urinary incontinence. To determine the different phases of the estrous cycle, female rats were monitored by daily vaginal smears and only those demonstrating at least two consecutive 4-day cycles were used in the study and killed on the day of proestrus. Tissues were collected in two independent experiments, the first for molecular biology studies, the second for morphology and western blotting. Sixty-four animals ( 32 females and 32 males) were included in the first experiment; eight animals were included in each time-point groups (sacrificed 14, 21, 40 DPI) for both male and female, and for un-injected animals. Twentyfour animals (12 females and 12 males) were include in the second experiment, were tissue was collected at 14 DPI. All animal protocols described herein were carried out according to the European Community Council Directives (86/609/EEC) and approved by the intramural ethical committee for animal experimentation of Bologna University and Ministry of Health, comply with the guidelines published in the NIH Guide for the Care and Use of Laboratory Animals.

\section{Histology, histochemistry and immunohistochemistry}

Six animals/group were included in this part of the study. EAE animals were killed at 14 DPI, i.e. during the acute phase of the disease. The lumbar tract of the spinal cord was rapidly dissected out, briefly washed in PBS and then fixed using a paraformaldehyde $4 \%+$ saturated picric acid 14\% solution in PBS $0.2 \mathrm{M}, \mathrm{pH} 6.9$ for 12 hours (h). Cryostat sections $(14 \mu \mathrm{m})$ were then collected from the spinal cord. The extent of inflammation, demyelination and astroglial rection was evaluated on tissue sections stained with hematoxylin and eosin to visualize infiltrate cells, with FluoroMyelin ${ }^{\mathrm{TM}}$ Fluorescence Myelin Staining (Molecular Probes, Eugene, OR) for the myelin sheaths. Indirect immunofluorescence (IF) procedures were used to visualize the anti-fibrillary acid protein (GFAP, Chemicon International Inc. Temecula, CA, USA). Briefly, sections were first incubated in $0.1 \mathrm{M}$ phosphate buffered saline (PBS) at room temperature for 10-30 min, followed by incubation at $4^{\circ} \mathrm{C}$ for $24 \mathrm{~h}$ in a humid atmosphere with the primary antibodies diluted in PBS containing $0.3 \%$ Triton X-100, v/v. After rinsing in PBS for $20 \mathrm{~min}$ $(2 \times 10 \mathrm{~min})$, sections were incubated at $37^{\circ} \mathrm{C}$ for $30 \mathrm{~min}$ in a humid atmosphere with the secondary antisera conjugated with different fluorochromes diluted in PBS/Triton $\mathrm{X}-100$ 0.3\%. Sections were then rinsed in PBS (as above) and mounted in glycerol containing 1,4-phenylendiamine $0.1 \mathrm{~g} / \mathrm{l}$ (Sigma). Images were taken by Olympus AX70-PROVIS microscope equipped with motorized z-stage control and F-VIEW II CCD Camera. The inflammatory infiltration was evaluated by two independent operators in blind on 5 replicate sections per animal, by counting the number and severity of cellular infiltrates over each, entire coronal section. Cellular infiltrates were scored as follows: 0 , none; 1 , a few inflammatory cells; 2 , organization of perivascular infiltrates; 3 , increasing severity of perivascular cuffing with extension into the adjacent tissue [59-61]. The inflammation score, expressed as score/section, derives from the sum of infiltration score in each cellular infiltrate. To minimize the bias due to random distribution of the demyelinating lesions, the FluoroMyelin and GFAP-staining were both measured in the fasciculus gracilis, and calculated as percentage positive areas using the Image ProPlus software (Imaging Research Inc, St. Catharines, Ont., Canada). Myelin sheath thickness was measured on confocal images (Olympus FluoView 500) using Image ProPlus software (MediaCybernetics, Bethesda, MD). The G-ratio (ratio of axon diameter to total fibre diameter) was calculated on confocal images by dividing the circumference of an axon without myelin by the circumference of the same axon including myelin. At least 250 fibers/group were included in the analysis.

\section{RNA isolation, reverse transcription and Semiquantitative real-time PCR}

Total RNA was prepared by following manufacture's instructions (Mini RNeasy Kit, Qiagen, Milan, Italy). RNAs were first subjected to DNase treatment $(0.1 \mathrm{U} / \mu \mathrm{l}$, $1 \times$ DNase buffer, $4 \mathrm{U} / \mu \mathrm{l}$ RNase inhibitor, all from Fermentas, Life Sciences, Milan, Italy) by incubating at $37^{\circ} \mathrm{C}$ for $30 \mathrm{~min}$. First strand cDNAs were obtained using $10 \mathrm{U} / \mu \mathrm{l}$ of the M-Moloney murine leukaemia virus (MuLV) reverse transcriptase enzyme (Fermentas), $1 \mathrm{mM}$ of each $\mathrm{d}$ (NTP)s (Fermentas), $5 \mu \mathrm{M}$ of $\mathrm{pd}(\mathrm{N})_{6}$ random primers (Roche, Molecular Biochemical's, Indianapolis, IN, USA) and $1 \mathrm{U} / \mu \mathrm{l}$ oligo $(\mathrm{dT})_{18}$ (Fermentas). In order to discard possible contamination of genomic DNA in isolated RNAs, one sample with no reverse transcriptase enzyme (no RT sample) was processed in parallel to the others and tested by real-time PCR for every pair of primers used. PCR reactions were performed with the Mx3005PTM real-time PCR system (Stratagene, CA, USA) using SYBRgreen I dye. All primers used for SYBR-green real-time PCR were designer with the Beacon Designer software (BD 5.0, Premier Biosoft International, Palo Alto, CA, USA); primer sequences have been included in Table 1 . The housekeeping gene GAPDH was used to normalize the amount of retro-transcribed mRNA used for PCR. Reactions were performed in a final volume of $25 \mu \mathrm{l}$ 


\begin{tabular}{|c|c|c|}
\hline Gene & Primer & Sequence \\
\hline BDNF & $\begin{array}{l}\text { Forward } \\
\text { reverse }\end{array}$ & $\begin{array}{l}5^{\prime} \text {-gtgacagtattagcgagtg-3' } \\
5^{\prime} \text {-gccttccttcgtgtaacc-3' }\end{array}$ \\
\hline GAD65 & $\begin{array}{l}\text { Forward } \\
\text { reverse }\end{array}$ & $\begin{array}{l}5^{\prime} \text {-gcccgctataagatgtctc--3' } \\
5^{\prime} \text {-aatcacactgtctgttcc-3' }\end{array}$ \\
\hline GAD67 & $\begin{array}{l}\text { Forward } \\
\text { Reverse }\end{array}$ & $\begin{array}{l}5^{\prime} \text {-ggcatcttccactccttc-3' } \\
5^{\prime} \text {-gacgactcttctcttccag-3' }\end{array}$ \\
\hline MBP & $\begin{array}{l}\text { Forward } \\
\text { reverse }\end{array}$ & $\begin{array}{l}5^{\prime} \text {-catccttgactccatcgg--3' } \\
5^{\prime} \text {-tttcatcttgggtcctctg-3' }\end{array}$ \\
\hline NGF & $\begin{array}{l}\text { Forward } \\
\text { reverse }\end{array}$ & $\begin{array}{l}5^{\prime} \text {-gacgactcttctcttccag-3' } \\
5^{\prime} \text {-cgtggctgtggtcttatctc-3' }\end{array}$ \\
\hline PDGF $\alpha R$ & $\begin{array}{l}\text { Forward } \\
\text { reverse }\end{array}$ & $\begin{array}{l}5^{\prime}-\text { ctggtgcctgcctcctac- } 3^{\prime} \\
5^{\prime}-\text { aactcgctggtcttgaacg-3' }\end{array}$ \\
\hline p75 & $\begin{array}{l}\text { Forward } \\
\text { reverse }\end{array}$ & $\begin{array}{l}5^{\prime} \text {-agtggcatctctgtggac-3' } \\
5^{\prime} \text {-ctacctcctcacgcttgg--3' }\end{array}$ \\
\hline trk-A & $\begin{array}{l}\text { Forward } \\
\text { reverse }\end{array}$ & $\begin{array}{l}5^{\prime} \text {-tgaatctgtcctccaatgc-3' } \\
5^{\prime} \text {-tgaagcgtctgtgtatgc }-3^{\prime}\end{array}$ \\
\hline GAPDH & $\begin{array}{l}\text { Forward } \\
\text { reverse }\end{array}$ & $\begin{array}{l}5^{\prime} \text {-ggcaagttcaatggcacagtcaag--3' } \\
5^{\prime} \text {-acatactcagcaccagcatcacc-3' }\end{array}$ \\
\hline
\end{tabular}

consisting on $1 \times$ master mix, (Fermentas) and $0.4 \mu \mathrm{M}$ of both forward and reverse primers. Two steps were performed: 1 . denaturation $\left(95^{\circ} \mathrm{C}, 10 \mathrm{~min}\right) ; 2$. annealing/ extension ( 40 cycles of: $95^{\circ} \mathrm{C}$ for $15 \mathrm{sec}, 60^{\circ} \mathrm{C}$ for $30 \mathrm{sec}$ ); at the end of PCR reaction the melting curve of amplified products was always performed.

The efficiency of each pair of used primers was calculated by amplifying cDNA serial dilutions in the conditions above described obtaining efficiency values in the range of 95-102\%. The $2^{\wedge(-\Delta \Delta C}$ T method was used for the calculation of gene expression relative to a given reference group $\left(C_{\mathrm{T}}\right.$, threshold cycle). When comparing gene expression between sexes, $\Delta \Delta C_{\mathrm{T}}$ was calculated as follow: $\Delta \Delta C_{\mathrm{T}}=$ $\left(C_{\mathrm{T} \text { target gene- }} C_{\mathrm{T} \text { GAPDH }}\right)$ female - $\left(C_{\mathrm{T} \text { target gene- }} C_{\mathrm{T}}\right.$ GAPDH $)$ male. When instead comparing gene expression between healthy (Control) and EAE animals at different phases of the disease, the $\Delta \Delta C_{\mathrm{T}}$ formula was: $\Delta \Delta C_{\mathrm{T}}=\left(C_{\mathrm{T}}\right.$ target gene $\left.-C_{\mathrm{T} \text { GAPDH }}\right)$ Control - $\left(C_{\mathrm{T}}\right.$ target gene $\left.{ }^{-} C_{\mathrm{T} \text { GAPDH }}\right)$ EAE acute $(14 \mathrm{DPI}), \Delta \Delta C_{\mathrm{T}}=\left(C_{\mathrm{T} \text { target gene }}{ }^{-} C_{\mathrm{T} \text { GAPDH }}\right)$ Control - $\left(C_{\mathrm{T}}\right.$ target gene- ${ }^{-} C_{\mathrm{T}}$ GAPDH $)$ EAE remission (21 DPI), $\Delta \Delta C_{\mathrm{T}}=\left(C_{\mathrm{T} \text { target gene }} C_{\mathrm{T} \text { GAPDH }}\right)$ Control $-\left(C_{\mathrm{T} \text { target }}\right.$ gene- $\left.^{-} C_{\mathrm{T} \text { GAPDH }}\right)$ EAE chronic (40 DPI).

The specificity of real-time PCR reactions was evidenced by the melting curve of the amplified products, obtaining a unique peak at the correspondent melting temperature $(\mathrm{Tm})$ (Figure $3 \mathrm{E})$. No $\mathrm{C}_{\mathrm{T}}$ was obtained after real-time PCR of no RT sample for any of the pair of primers used. Template controls gave always no $C_{\mathrm{T}}$ as well. Random amplified products were resolved in a $2.5 \%$ agarose gel and TAE electrophoresis buffer, obtaining a unique band of the expected size. DNA marker of 100 bp ladder (Fermentas) was used.

\section{Western blotting procedure}

Tissue homogenates were prepared using a lysing buffer consisting on $10 \mathrm{mM}$ Hepes, $1 \mathrm{mM}$ DTT, pH 7.5 and protease inhibitor cocktail (Sigma). Equal amounts of protein, concentrations determined by Lowry method with the Protein assay kit (Bio-Rad, Hercules, California, USA), were separated in 15\% SDS-polyacrylamide gels and electroblotted to nitrocellulose membranes. In order to block nonspecific protein binding sites, filters were incubated with blocking solution (Pierce, Rockford, IL, USA) for $2 \mathrm{~h}$ at room temperature and primary antibodies were then incubated overnight at $4^{\circ} \mathrm{C}$. After washing for 1 hour with TTBS (TBS-0.05\% Tween-20), filters were incubated with secondary antibodies for $30 \mathrm{~min}$ at room temperature and washed again for another hour. Rabbit polyclonal antiMBP (DAKO), dilution 1:2000 and GAPDH (glyceraldehyde 3-phosphate dehydrogenase) (Millipore, Milan, Italy), dilution 1:150 were used as primary antibodies while antirabbit $(1: 30,000)$ and anti-mouse (1:2000), respectively, antiserum conjugated to horseradish peroxidase (DAKO) were used as secondary antibody. Finally, proteins were detected using an ECL chemioluminescent kit (Pierce) and exposition to radiographic film. Densitometric analysis was performed using the AIS Imaging System software (Ontario, Canada) and the data obtained statistically analysed and represented using PrismGraph software (GraphPad Software, San Diego, CA, USA). Seven animals/group were used to perform these studies.

\section{Data presentation and statistical analysis}

For mRNAs expression data, we first analyzed the difference between female and male control animals (data normalized vs female, because the disease is usually induced in female rats.). Student's t test was used for the statistical analysis. Since the aim of the study was to investigate the disease effect at different time point in male and female rats, we then analyzed the disease and gender influence by two-way ANOVA and Bonferroni post-test. Results for two-way ANOVA are reported in the figures and figure legends. Morphological data were analyzed by Student's t test, and clinical data by two-way ANOVA. Results were considered significant when the probability of their occurrence by chance alone was less than $5 \%$. GraphPad Software (San Diego, CA, USA) was used for statistics and graph preparation.

\section{Abbreviations}

BDNF: Brain-derived neurotrophic factor; CFA: complete Freund's adjuvant; CNS: Central nervous system; DPI: day post-immunization; EAE: experimental allergic encephalomyelitis; GAD: $\gamma$-aminobutyric acid decarboxylase; GABA: $\gamma^{-}$ aminobutyric acid; GAPDH: glyceraldehyde 3-phosphate dehydrogenase; GFAP: anti-fibrillary acid protein; MBP: myelin basic protein; MOG: myelin oligodendrocyte glycoprotein; MS: Multiple sclerosis; NGF: Nerve growth factor; OPCs: oligodendrocyte precursor cells; PDGF: platelet-derived growth factor. 


\section{Acknowledgements}

This work was supported by AISM-FISM (LG), Health Sciences and Technology - Interdepartmental Center for Industrial Research (HST-ICIR), University of Bologna and Assessorato alle attività Produttive (LC); Fondazione IRET, Ozzano Emilia (LG). The financial support of Fondazione Italiana Sclerosi Multipla (2010/23) to RC Melcangi is gratefully acknowledged.

\section{Author details \\ 'Health Sciences and Technology - Interdepartmental Center for Industrial Research (HST-ICIR), University of Bologna, Via Tolara di Sopra 50, 40064 Ozzano Emilia, Italy. ${ }^{2}$ Department of Veterinary Medicine, University of Bologna, Via Tolara di Sopra 50, 40064 Ozzano Emilia, Italy. ${ }^{3}$ Dept. of Endocrinology, Pathophysiology and Applied Biology - Center of Excellence on Neurodegenerative Diseases, University of Milan, Via Balzaretti 9, 20133 Milano, Italy}

\section{Authors' contributions}

AM: carried out the molecular biology studies. GD: carried out the EAE induction, the histology, histochemistry, immunohistochemistry and morphometry. MF: carried out molecular biology studies, Western blotting procedure and statistical analysis. SS: carried out the histology, histochemistry and immunohistochemistry and morphometry. LL: carried out the EAE induction and followed animals clinically. SG: carried out Western blotting procedure. RCM: participated in the design of the study and drafted the manuscript. LC: conceived of the study, participated in its design and coordination and redacted the manuscript. LG: participated in the design of the study and redacted the manuscript. All authors read and approved the final manuscript.

\section{Competing interests}

The authors declare that they have no competing interests.

Received: 25 August 2011 Accepted: 24 January 2012

Published: 24 January 2012

\section{References}

1. Hauser SL, Oksenberg JR: The neurobiology of multiple sclerosis: genes, inflammation, and neurodegeneration. Neuron 2006, 52:61-76.

2. Hawkins SA, McDonnell GV: Benign multiple sclerosis? Clinical course, long term follow up, and assessment of prognostic factors. J Neurol Neurosurg Psychiatry 1999, 67:148-52.

3. Confavreux C, Vukusic S, Adeleine P: Early clinical predictors and progression of irreversible disability in multiple sclerosis: an amnesic process. Brain 2003, 126:770-782.

4. Tomassini V, Pozzilli C: Sex hormones: a role in the control of multiple sclerosis? Expert Opin Pharmacother 2006, 7:857-868.

5. Schwendimann RN, Alekseeva N: Gender issues in multiple sclerosis. Int Rev Neurobiol 2007, 79:377-392.

6. Cosgrove KP, Mazure CM, Staley JK: Evolving knowledge of sex differences in brain structure, function, and chemistry. Biol Psychiatry 2007, 62:847-855.

7. Hsu JL, Leemans A, Bai CH, Lee CH, Tsai YF, Chiu HC, Chen WH: Gender differences and age-related white matter changes of the human brain: a diffusion tensor imaging study. Neurolmage 2008, 39:566-577.

8. Highley JR, DeLisi LE, Roberts N, Webb JA, Relja M, Razi K, Crow TJ: Sexdependent effects of schizophrenia: an MRI study of gyral folding, and cortical and white matter volume. Psychiatry Res 2003, 124:11-23.

9. Bramlett HM, Dietrich WD: Pathophysiology of cerebral ischemia and brain trauma: similarities and differences. I Cereb Blood Flow Metab 2004, 24:133-150.

10. Webber KM, Casadesus G, Marlatt MW, Perry G, Hamlin CR, Atwood CS, Bowen RL, Smith MA: Estrogen bows to a new master: the role of gonadotropins in Alzheimer pathogenesis. Ann N Y Acad Sci 2005, 1052:201-209.

11. Polman $\mathrm{CH}$, Uitdehaag BM: New and emerging treatment options for multiple sclerosis. Lancet Neurol 2003, 2:563-566.

12. Melcangi RC, Garcia-Segura LM: Sex-specific therapeutic strategies based on neuroactive steroids: In search for innovative tools for neuroprotection. Horm Behav 2010, 57:2-11.
13. Calzà L, Giardino L, Pozza M, Micera A, Aloe L: Time-course changes of nerve growth factor, corticotropin-releasing hormone, and nitric oxide synthase isoforms and their possible role in the development of inflammatory response in experimental allergic encephalomyelitis. Proc Natl Acad Sci USA 1997, 94:3368-3373.

14. Calzà L, Giardino L, Pozza M, Bettelli C, Micera A, Aloe L: Proliferation and phenotype regulation in the subventricular zone during experimental allergic encephalomyelitis: in vivo evidence of a role for nerve growth factor. Proc Natl Acad Sci USA 1998, 95:3209-3214.

15. Calza L, Fernández M, Giuliani A, Aloe L, Giardino L: Thyroid hormone activates oligodendrocyte precursors and increases a myelin-forming protein and NGF content in the spinal cord during experimental allergic encephalomyelitis. Proc Natl Acad Sci USA 2002, 99:3258-3263.

16. Fernández M, Giuliani A, Pirondi S, D'intino G, Giardino L, Aloe L, LeviMontalcini $R$, Calza' L: Thyroid hormone administration facilitates remyelination in chronic experimental demyelinating-inflammatory disease. Proc Natl Acad Sci USA 2004, 101:16363-16368.

17. Giardino L, Giuliani A, Fernández M, Calzà L: Spinal motoneurone distress during experimental allergic encephalomyelitis. Neuropathol Appl Neurobiol 2004, 30:522-531.

18. D'Intino G, Paradisi M, Fernández M, Giuliani A, Aloe L, Giardino L, Calzà L: Cognitive deficit associated with cholinergic and nerve growth factor down-regulation in experimental allergic encephalomyelitis in rats. Proc Natl Acad Sci USA 2005, 102:3070-3075.

19. Caruso D, Pesaresi M, Maschi O, Giatti S, Garcia-Segura LM, Melcangi RC: Effect of short-and long-term gonadectomy on neuroactive steroid levels in the central and peripheral nervous system of male and female rats. J Neuroendocrinol 2010, 22:1137-1147.

20. Giatti S, D'Intino G, Maschi O, Pesaresi M, Garcia-Segura LM, Calza L, Caruso D, Melcangi RC: Acute experimental autoimmune encephalomyelitis induces sex dimorphic changes in neuroactive steroid levels. Neurochem Int 2010, 56:118-127.

21. MacKenzie-Graham A, Tinsley MR, Shah KP, Aguilar C, Strickland LV, Boline J, Martin M, Morales L, Shattuck DW, Jacobs RE, Voskuhl RR, Toga AW: Cerebellar cortical atrophy in experimental autoimmune encephalomyelitis. Neurolmage 2006, 32:1016-1023.

22. Baracskay KL, Kidd GJ, Miller RH, Trapp BD: NG2-positive cells generate A2B5-positive oligodendrocyte precursor cells. Glia 2007, 55:1001-1010.

23. Tzakos AG, Troganis A, Theodorou V, Tselios T, Svarnas C, Matsoukas J, Apostolopoulos V, Gerothanassis IP: Structure and function of the myelin proteins: current status and perspectives in relation to multiple sclerosis. Curr Med Chem 2005, 12:1569-1587.

24. Greer JM, McCombe PA: Role of gender in multiple sclerosis: Clinical effects and potential molecular mechanisms. J Neuroimmunol 2011, 234:7-18.

25. Kuhlmann T, Goldschmidt T, Antel J, Wegner C, Konig F, Metz I, Bruck W: Gender differences in the histopathology of MS? J Neurol Sci 2009, 286:86-91

26. Gold R, Linington C, Lassmann $\mathrm{H}$ : Understanding pathogenesis and therapy of multiple sclerosis via animal models: 70 years of merits and culprits in experimental autoimmune encephalomyelitis research. Brain 2006, 129:1953-1971.

27. Fuller AC, Kang B, Kang HK, Yahikozowa H, Dal Canto MC, Kim BS: Gender bias in Theiler's virus-induced demyelinating dosease correlates with the level of antiviral immune responses. J Immunol 2005, 175:3955-3963.

28. Reddy J, Waldner H, Zhang X, Illes Z, Wucherpfennig KW, Sobel RA, Kuchroo VK: Cutting edge: $C D 4+C D 25+$ regulatory $T$ cells contribute to gender differences in susceptibility to experimental autoimmune encephalomyelitis. J Immunol 2005, 175:5591-5595.

29. Staykova MA, Cowden W, Willenborg DO: Macrophages and nitric oxide as the possible cellular and molecular basis for strain and gender differences in susceptibility to autoimmune central nervous system inflammation. Immunol Cell Biol 2002, 80:188-97.

30. De Maio A, Torres MB, Reeves RH: Genetic determinants influencing the response to injury, inflammation, and sepsis. Shock 2005, 23:11-17.

31. Sinha S, Kaler LJ, Proctor TM, Teuscher C, Vandenbark AA, Offner H: IL-13mediated gender difference in susceptibility to autoimmune encephalomyelitis. J Immunol 2008, 180:2679-2685.

32. Gry M, Rimini R, Strömberg $S$, Asplund A, Pontén F, Uhlén M, Nilsson P: Correlations between RNA and protein expression profiles in 23 human cell lines. BMC Genomics 2009, 10:365-379. 
33. Greenbaum D, Colangelo C, Williams K, Gerstein M: Comparing protein abundance and mRNA expression levels on a genomic scale. Genome Biol 2003, 4:117-225.

34. Zhao C, Dahlman-Wright, Gustafsson J-A: Estrogen receptor $\beta$ : an overview and update. Nuclear Receptor Signaling 2008, 6:1-10.

35. Cerghet M, Skoff RP, Bessert D, Zhang Z, Mullins C, Ghandour MS: Proliferation and death of oligodendrocytes and myelin proteins are differentially regulated in male and female rodents. J Neurosci 2006, 26:1439-1447.

36. Cerghet M, Skoff RP, Swamydas M, Bessert D: Sexual dimorphism in the white matter of rodents. J Neurol Sci 2009, 286:76-80.

37. Slavin DA, Bucher AE, Degano AL, Soria NW, Roth GA: Time course of biochemical and immunohistological alterations during experimental allergic encephalomyelitis. Neurochem Int 1996, 29:597-605.

38. Li WW, Penderis J, Zhao C, Schumacher M, Franklin RJ: Females remyelinate more efficiently than males following demyelination in the aged but not young adult CNS. Exp Neurol 2006, 202:250-254.

39. Taylor LC, Gilmore W, Matsushima G: SJL Mice Exposed to Cuprizone Intoxication Reveal Strain and Gender Pattern Differences in Demyelination. Brain Pathol 2009, 19:467-479.

40. MacKenzie-Graham A, Tiwari-Woodruff SK, Sharma G, Aguilar C, Vo KT, Strickland LV, Morales L, Fubara B, Martin M, Jacobs RE, Johnson GA, Toga AW, Voskuhl RR: Purkinje cell loss in experimental autoimmune encephalomyelitis. Neurolmage 2009, 48:637-651.

41. Sastry BR, Morishita W, Yip S, Shew T: GABA-ergic transmission in deep cerebellar nuclei. Prog Neurobiol 1997, 53:259-71.

42. NGF and related molecules in health and disease. In Progress In Brain Research. Elsevier Edited by: Aloe L, Calza L 2003, 146.

43. Takei Y, Laskey R: Interpreting crosstalk between TNF-alpha and NGF: potential implications for disease. Trends Mol Med 2008, 14:381-388.

44. Schulte-Herbrüggen $\mathrm{O}$, Braun $\mathrm{A}$, Rochlitzer $\mathrm{S}$, Jockers-Scherübl MC, Hellweg R: Neurotrophic factors-a tool for therapeutic strategies in neurological, neuropsychiatric and neuroimmunological diseases? Curr Med Chem 2007, 14:2318-2329.

45. Bonini S, Rasi G, Bracci-Laudiero ML, Procoli A, Aloe L: Nerve growth factor: neurotrophin or cytokine? Int Arch Allergy Immunol 2003, 131:80-84.

46. Villoslada P, Hauser SL, Bartke I, Unger J, Heald N, Rosenberg D, Cheung SW, Mobley WC, Fisher S, Genain CP: Human nerve growth factor protects common marmosets against autoimmune encephalomyelitis by switching the balance of T helper cell type 1 and 2 cytokines within the central nervous system. J Exp Med 2000, 191:1799-1806.

47. Parvaneh Tafreshi A: Nerve growth factor prevents demyelination, cell death and progression of the disease in experimental allergic encephalomyelitis. Iran J Allergy Asthma Immunol 2006, 5:177-1781.

48. Damarjian TG, Craner MJ, Black JA, Waxman SG: Upregulation and colocalization of p75 and $\mathrm{Na}_{\mathrm{v}} 1.8$ in Purkinje neurons in experimental autoimmune encephalomyelitis. Neurosci Lett 2004, 369:186-190.

49. Florez-McClure ML, Linseman DA, Chu CT, Barker PA, Bouchard RJ, Le SS, Laessig TA, Heidenreich KA: The p75 neurotrophin receptor can induce autophagy and death of cerebellar Purkinje neurons. J Neurosci 2004, 24:4498-4509.

50. Levi-Montalcini R, Angeletti PU: Hormonal control of the NGF content in the submaxillary glands of mice. Int Ser Monogr Oral Biol 1964, 3:129-141.

51. Lipps BV: Age and sex-related difference in levels of nerve growth factor in organs of Balb/c mice. J Nat Toxins 2002, 11:387-391.

52. Serrano T, Lorigados LC, Armenteros S: Nerve growth factor levels in normal human sera. Neuroreport 1996, 8:179-181.

53. Lang UE, Gallinat J, Danker-Hopfe H, Bajbouj M, Hellweg R: Nerve growth factor serum concentrations in healthy human volunteers: physiological variance and stability. Neurosci Lett 2003, 344:13-16.

54. Tsutsui K: Neurosteroids in the Purkinje cell: biosynthesis, mode of action and functional significance. Mol Neurobiol 2008, 37:116-125.

55. Bimonte-Nelson HA, Granholm AC, Nelson ME, Moore AB: Patterns of neurotrophin protein levels in male and female Fischer 344 rats from adulthood to senescence: how young is "young" and how old is "old"? Exp Aging Res 2008, 34:13-26.

56. Sajdel-Sulkowska EM, Xu M, Koibuchi N: Cerebellar brain-derived neurotrophic factor, nerve growth factor, and neurotrophin-3 expression in male and female rats is differentially affected by hypergravity exposure during discrete developmental periods. Cerebellum 2009, $8: 454-462$
57. Acs P, Kipp M, Norkute A, Johann S, Clarner T, Braun A, Berente Z, Komoly S, Beyer C: 17beta-estradiol and progesterone prevent cuprizone provoked demyelination of corpus callosum in male mice. Glia 2009, 57:807-814.

58. Garay L, Gonzalez Deniselle MC, Gierman L, Meyer M, Lima A, Roig P, De Nicola AF: Steroid protection in the experimental autoimmune encephalomyelitis model of multiple sclerosis. Neuroimmunomodulation 2008, 15:76-83.

59. Hickey WF, Cohen JA, Burns JB: A quantitative immunohistochemical comparison of actively versus adoptively induced experimental allergic encephalomyelitis in the Lewis rat. Cell Immunol 1987, 109:272-281.

60. Zang Y, Hong J, Robinson R, Li S, Rivera VM, Zhang JZ: Immune regulatory properties and interactions of copolymer-I and beta-interferon 1a in multiple sclerosis. J Neuroimmunol 2003, 137:144-153.

61. Cabrelle A, Dell'Aica I, Melchiori L, Carraro S, Brunetta E, Niero R, Scquizzato E, D'Intino G, Calzà L, Garbisa S, Agostini C: Hyperforin downregulates effector function of activated $T$ lymphocytes and shows efficacy against Th1-triggered CNS inflammatory-demyelinating disease. J Leukoc Biol 2008, 83:212-219.

doi:10.1186/1471-2202-13-12

Cite this article as: Massella et al:: Gender effect on neurodegeneration and myelin markers in an animal model for multiple sclerosis. BMC Neuroscience 2012 13:12.

\section{Submit your next manuscript to BioMed Central and take full advantage of:}

- Convenient online submission

- Thorough peer review

- No space constraints or color figure charges

- Immediate publication on acceptance

- Inclusion in PubMed, CAS, Scopus and Google Scholar

- Research which is freely available for redistribution

Submit your manuscript at www.biomedcentral.com/submit
C Biomed Central 